\title{
A clinico-radiographic and histomorphometric analysis of alveolar ridge preservation using calcium phosphosilicate, PRF, and collagen plug
}

\author{
Tarun Kumar AB ${ }^{1}$, Chaitra N. T. ${ }^{2}$, Gayatri Divya PS $^{3^{*}} \mathbb{D}$, M. G. Triveni ${ }^{1}$ and Dhoom Singh Mehta ${ }^{1}$
}

\begin{abstract}
Background: Tooth extraction commonly leads to loss of residual alveolar ridge, thus compromising the room available for the implant placement. To combat the post-extraction alveolar loss, alveolar ridge preservation is practiced, with the advent of the biomaterial available. The purpose of this study was to assess the efficiency of calcium phosphosilicate biomaterial in alveolar ridge preservation. Twenty patients indicated for extraction were selected followed by socket grafting using calcium phosphosilicate. Implant placement was done 6 months postoperatively during which a core was harvested from the preserved sockets. Clinico-radiographic measurements of hard and soft tissues were taken at baseline and 6 months post-grafting.

Results: There were no significant changes in the radiographic and soft tissue parameters while significant changes in hard tissue parameters with $1.9 \mathrm{~mm}(p=0.013)$ gain in mid-buccal aspect and $1.1 \mathrm{~mm}(p=0.019)$ loss in horizontal bone width were observed. The histomorphometric evaluation depicted the vital bone volume of $54.5 \pm$ $16.76 \%$, non-mineralized tissue $43.50 \pm 15.80 \%$, and residual material $2.00 \pm 3.37 \%$.

Conclusion: The implants placed in these preserved ridges presented $100 \%$ success rate with acceptable stability after a 1-year follow-up, concluding calcium phosphosilicate is a predictable biomaterial in alveolar ridge preservation.
\end{abstract}

Keywords: Alveolar ridge preservation, Atraumatic extraction, Calcium phosphosilicate, Histomorphometry, Implant

\section{Background}

The predictability of dental implants was increased with the revolutionary phenomenon of osseointegration. A major emphasis is now over the three-dimensionally ideal placement of the implant for the efficient function of the restoration to be placed. The most acceptable and desirable position of the implant would be in the alveolar socket itself to mimic the natural dentition [1]. Alveolar process undergoes disuse atrophy after extraction. Schropp stated that the post-extraction healing and residual ridge dimensions are likely to be dependent on the alveolar crestal bone levels at the extraction site rather than that of the adjacent tooth [2]. Hence, to prevent the loss of residual ridge, atraumatic

\footnotetext{
* Correspondence: drdivyagayatri@gmail.com

${ }^{3}$ Consultant Periodontist, Guntur, Andhra Pradesh 522006, India

Full list of author information is available at the end of the article
}

extraction is indicated without flap reflection. Preservation of the extraction socket by socket grafting would aid in minimal post-extraction resorption for prosthetically driven implant placement into the previous extraction socket [3]. Benex extractor is one such system used for atraumatic exodontia [4].

Socket preservation is a technique which aids in reducing the post-extraction dimensional changes in alveolar bone [5]. The biomaterial or combination of materials with anticipated regeneration capacity is invited for ridge augmentation procedures. Among the plethora of biomaterials available, alloplasts, the synthetic bone substitutes are widely accepted due to less patient morbidity, no demand for a secondary surgical site, reduced graft rejection, etc. Calcium phosphosilicate is one such alloplastic material which is easy to 
manipulate, readily packable, and a good hemostatic properties. Thus, this biomaterial was selected for preserving the extraction sockets.

Platelet-rich fibrin (PRF) and collagen plug were used as an adjunctive for the graft adopting the principles of guided bone regeneration [6, 7]. This study aims at clinical and histological evaluation of a traumatically extracted and grafted socket with calcium phosphosilicate putty enriched with PRF and collagen plug, 6 months after grafting. Further predictability of the grafted socket was done, evaluating the stability quotients of the implants and radiographic assessment of the crestal bone levels around the implant.

\section{Materials and methods}

This longitudinal prospective interventional clinical study was conducted on 20 (8 male and 12 female) healthy subjects within the age range of $18-50$ years, with hopeless teeth indicated for extraction (Fig. 1a, b).

Inclusion criteria for selection in the present study considered the following conditions which were indicated for extraction like

- Root fractures

- Endodontic failures

- Caries

- Internal root resorption

- External root resorption

- Tooth with open apex

- Over-retained deciduous tooth

The study protocol was commenced after obtaining approval from the institutional review board according to the principles of the World Medical Health
Association Declaration of Helsinki 2000 for medical research in human subjects. A detailed medical and dental history with required laboratory blood investigations was done. It was made sure that all the patients included in the study belonged to ASA class I physical status. Orthopantamographs (OPG) and intraoral periapical radiographs of the area of interest were taken. Diagnostic casts were made, and customized acrylic stents were fabricated for standardized measurement of soft tissue parameters and marginal bone height levels at the baseline and postoperatively. Clinical parameters like the following were measured at the baseline pre-operatively and 6 months postoperative:

- Gingival index (Loe and Sillness) [8],

- Plaque index (Sillness and Loe) [9],

- Marginal bone levels at four sites (mid-buccal, midpalatal, mid-mesial, and mid-distal) using the stent [9], (Fig. 2e-h)

- The bucco-palatal/bucco-lingual width of the socket [10],

- Keratinized mucosa index (Cox and Zarb) [11],

- Papillary height measurement using stent [12]. (Fig. 2a-d)

Oral prophylaxis was done 4 weeks before the extraction, and instructions were given on oral hygiene maintenance and its significance on the treatment prognosis. Patients were given one capsule of Augmentin $625 \mathrm{mg}$ $12 \mathrm{~h}$ before and the same dose was given along with Ketorolac $10 \mathrm{mg} 1 \mathrm{~h}$ before the procedure. One tablet of Alprazolam one night before was considered for apprehensive patients.

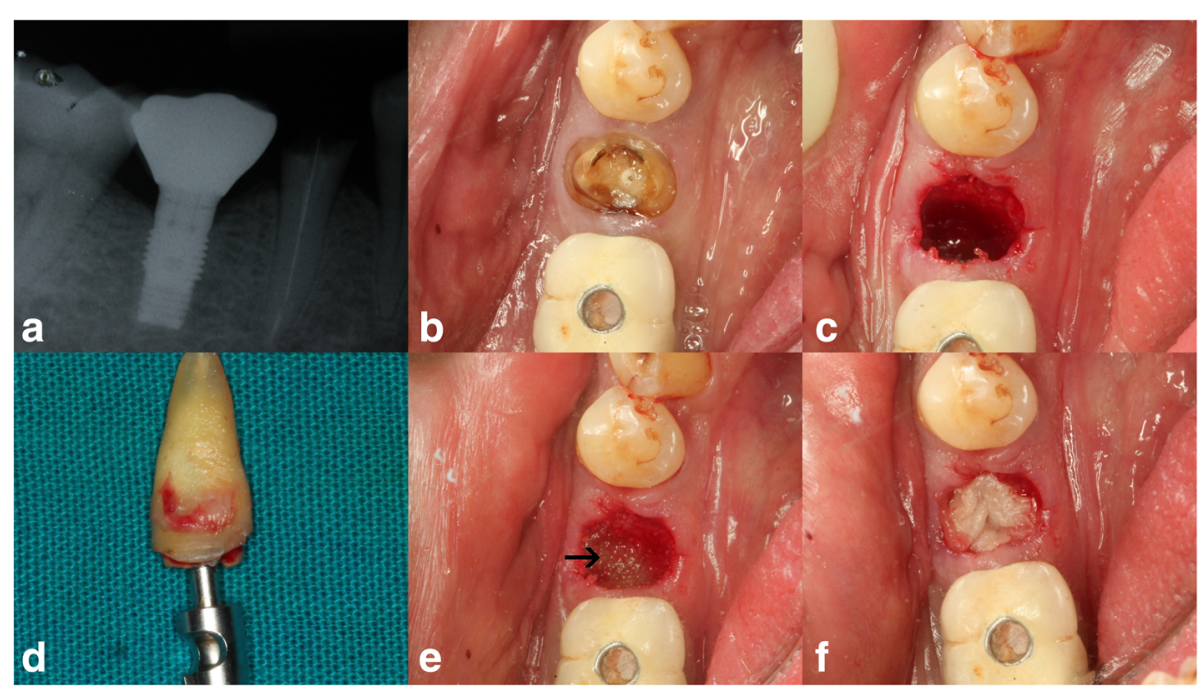

Fig. 1 Pre-operative radiographic (a) and clinical representation of premolar indicated for extraction (b). Atraumatic extraction done (c) using the Benex extraction system (d) followed by socket grafting with calcium phosphosilicate biomaterial (e pointed using arrow) and PRF placement (f) 


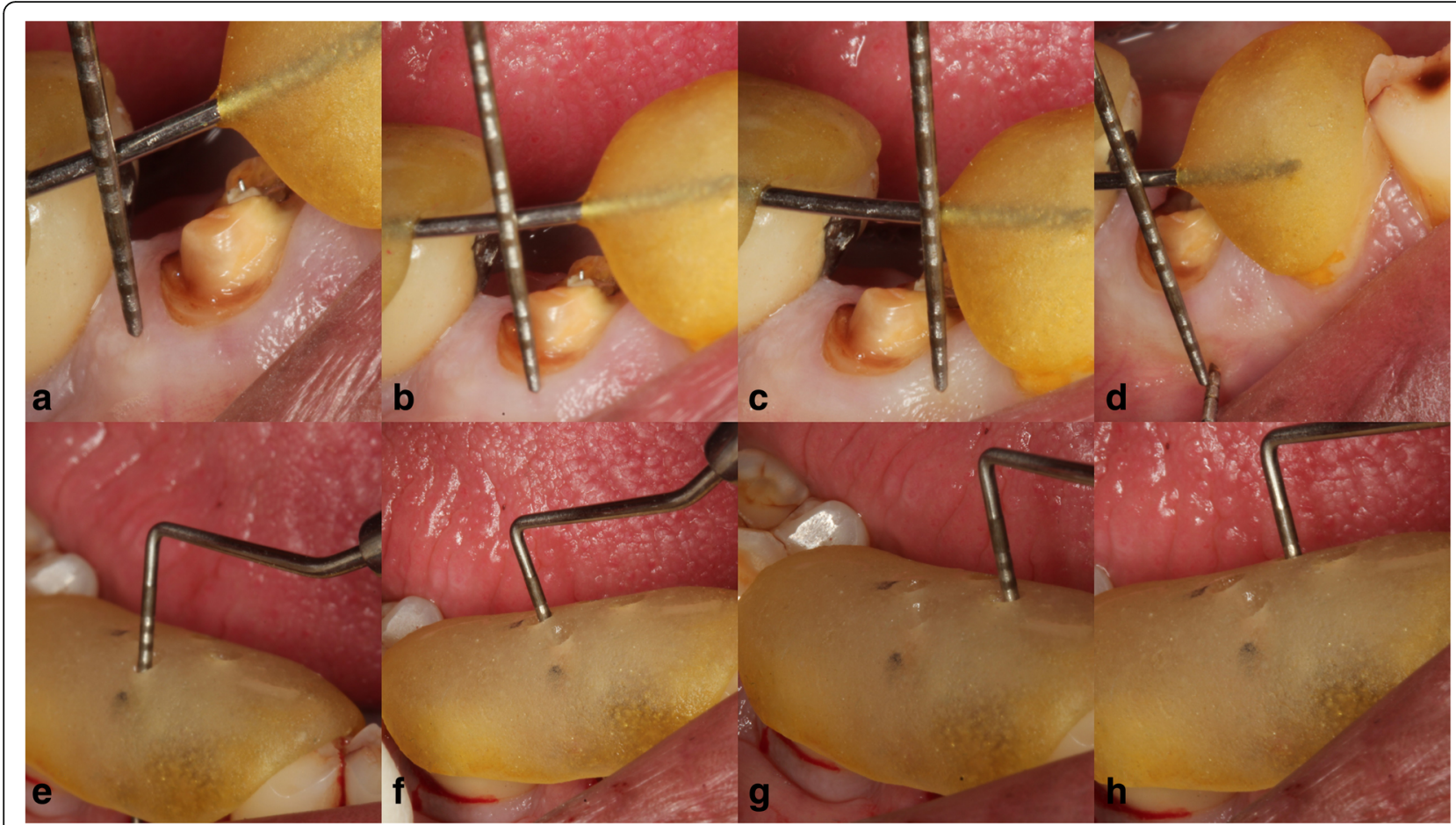

Fig. 2 Measurement of keratinized gingival height distal (a), mid-buccal (b), mesial (c), and width of keratinized gingiva (d) using stent. A different stent with access holes fabricated was used for marginal bone measurement in mid-buccal (e), mid-distal (f), mid-mesial (g), and midlingual (h) locations following the extraction

\section{Surgical procedure}

On the day of extraction, firstly, PRF was prepared using Choukron's protocol. Two percent Xylocaine $\mathrm{HCl}$ with adrenaline 1:80,000, crevicular, or sulcular incisions were placed around the indicated tooth with No: 15C Bard-Parker blade. Periotome followed by the Benex system was used for extraction (Fig. 1c, d). The extraction socket was thoroughly irrigated and curetted, followed by an exploration of the extraction socket using UNC-15 probe for fenestration or dehiscence on the buccal plate, if any. Socket grafting was then done using calcium phosphosilicate (Novabone ${ }^{\circ}$ putty) graft, which was directly delivered to the extraction socket with the cartridge (Fig. 1e). The graft material was packed in 3-4 bulk amounts until the extraction sockets were completely filled to the height of the alveolar crest followed by PRF placement over the graft (Fig. 1f). Then, a resorbable collagen plug (ACE Surgical Supply Co., Inc.) was placed over the PRF, and mattress sutures (5-0 polyamide, Trulon, Sutures India, India) were given which were removed after 1 week. The following post-surgical instructions and medication were given:

- Cap. Augmentin 625 mg was given twice and Tab. Ketorol thrice daily for 5 days.
- Rinse mouth gently using an oral rinse (Chlorhexidine gluconate) twice daily for 15 days.

- Patients were prohibited from chewing or putting any kind of load in the surgical area.

- The patient was asked to apply an ice pack over the operated area intermittently for the first $12 \mathrm{~h}$ after the surgery.

- In case prolonged bleeding persisted, patients were asked to report to the hospital.

There was no evidence of any complication during the course of study. The clinical parameters, recorded at the baseline, were re-recorded for the full mouth as well as for the selected sites, at 6 months after extraction using the same stent to standardize the measurements and minimize the error. Only 16 patients ( 6 males, 10 females) returned for the follow-up examinations at 6 months. The plaque index and gingival index were taken for the full mouth, while keratinized mucosa index, soft tissue height, and marginal bone levels were recorded at the study site at baseline and 6-month intervals.

A bone core was harvested from the center of the socket using a trephine bur during implant placement. Further evaluation of the grafted socket was done by studying the implant stability using the Osstell ISQ system and marginal bone around the implant. Stability was measured at 
the implant placement and 4 months later, during loading [13]. The alveolar crestal bone levels of the implants were measured during the loading and 1-year post-loading using intraoral periapical radiographs. All the radiographs were taken by a single operator using the long-cone technique to minimize the inter-operator variability in the radiographic measurements.

\section{Outcome measures}

The primary outcome measures of this interventional prospective clinical study are to study the:

- Soft tissue profile in grafted sites baseline and 6 months after socket grafting

- Marginal crestal bone changes in grafted sites clinically 6 months post-grafting

- Patterns of bone regeneration in the grafted sites histologically after 6 months of socket grafting

\section{Histomorphometric analysis}

Harvested cores were dehydrated with a graded series of alcohols for 9 days. Following dehydration, the specimens were infiltrated with a light-curing embedding resin (Technovit 7200 VLC, Heraeus Kulzer, Wehrheim, Germany) and were then ground into thin longitudinal sections in apicocoronal direction. The ground sections were stained with Stevenel Blue and Von Gieson fuchsin stain and observed under polarized light microscope at low $(\times 10)$, medium $(\times 20)$, high $(\times 40)$, and very high magnifications $(\times 100)$.

The secondary outcome measures are:

- Stability of implants placed in the grafted socket using resonance frequency analysis during the placement of the implant and 4 months postoperatively

- Changes in the crestal bone height during the implant placement, loading (4 months postoperatively), and 1-year post-loading

\section{Results}

\section{Clinical parameters}

The plaque index was decreased and the gingival index was increased, indicating good plaque control measures during the course of the study. The variation of keratinized mucosa index, soft tissue width, and height at mesial, distal, and mid-buccal site were observed using stent pre-operative and at 6 months postoperative. The changes in soft tissue were statistically nonsignificant throughout the study (Table 1).

Similarly, the variation of marginal bone level height and width were determined using a stent at the baseline and at 6 months postoperatively. On the mid-buccal site, at the baseline mean was $11.16 \pm 1.73 \mathrm{~mm}$, and at 6 months, it increased to $13.03 \pm 2.2 \mathrm{~mm}$ with a mean difference of $-1.9 \mathrm{~mm}$ which was statistically significant $(p=0.013)$. The horizontal width mean of the marginal bone at the baseline was $7 \pm 1.11 \mathrm{~mm}$ while it decreased to $5.9 \pm 1.35 \mathrm{~mm}$ at 6 months with a mean difference of $1.10 \mathrm{~mm}$ which was statistically significant $(p=0.019)$. The radiographic parameters which evaluated the postextraction bone changes were statistically not significant throughout the course of the study. For intragroup variation, Wilcoxon's signed-rank test and paired $t$ test were performed.

On the histomorphometric analysis, the cores revealed a new bone formation in all the grafted sockets. The mean percentage of the vital bone volume was $54.5 \pm 16.76$,

Table 1 Statistical analysis of variation clinical parameters

\begin{tabular}{|c|c|c|c|c|c|c|c|c|}
\hline & & & \multicolumn{2}{|c|}{ Baseline } & \multicolumn{2}{|c|}{ Post-op 6 months } & \multirow{2}{*}{$\begin{array}{l}\text { Mean } \\
\text { difference }\end{array}$} & \multirow{2}{*}{$\begin{array}{l}P \text { value } \\
\text { significance }\end{array}$} \\
\hline & & & Mean & SD & Mean & SD & & \\
\hline \multirow[t]{5}{*}{ Soft tissue measurement using stent } & Vertical & Mesial & 6.75 & 1.5 & 6.94 & 1.3 & -0.19 & $0.19 \mathrm{NS}$ \\
\hline & & Mid-buccal & 8.63 & 1.8 & 8.6 & 1.81 & 0.031 & $0.92 \mathrm{NS}$ \\
\hline & & Distal & 7.16 & 1.65 & 7.38 & 1.31 & -0.22 & 0.443 NS \\
\hline & Horizontal & & 2 & 0.41 & 2.13 & 0.5 & -0.13 & $0.41 \mathrm{NS}$ \\
\hline & Vertical & Mid-buccal & 11.16 & 1.73 & 13.03 & 2.2 & -1.9 & 0.0135 \\
\hline \multirow[t]{3}{*}{ Marginal bone level using stent } & & Mid-palatal/lingual & 11.75 & 2.5 & 12.5 & 2.5 & -0.75 & $0.4 \mathrm{~S}$ \\
\hline & & Mid-mesial & 11.4 & 1.6 & 12.0 & 1.6 & -0.56 & 0.3253 NS \\
\hline & & Mid-distal & 11.4 & 1.72 & 12.0 & 1.7 & -0.6 & $0.34 \mathrm{NS}$ \\
\hline Using stent & Horizontal & Bucco-lingual/palatal & 7 & 1.11 & 5.9 & 1.35 & 1.10 & $0.019 \mathrm{~S}$ \\
\hline \multirow[t]{2}{*}{ Radiographic bone level } & & Mesial & 1.25 & 1.06 & 1.69 & 1.19 & -0.438 & $0.14 \mathrm{NS}$ \\
\hline & & Distal & 1.28 & 1.06 & 1.47 & 1.08 & -0.18 & 0.083 NS \\
\hline \multicolumn{3}{|l|}{ ISQ value } & 69.13 & 4.22 & 71.31 & 4.50 & $2.18 \pm 0.28$ & $0.000 \mathrm{~S}$ \\
\hline \multicolumn{3}{|c|}{ Crestal bone level (loading and 1 year post-op) } & 0.83 & 0.30 & 1.06 & 0.27 & $0.23 \pm 0.03$ & $0.000 \mathrm{~S}$ \\
\hline
\end{tabular}


non-mineralized tissue or marrow spaces $43.50 \pm 15.80$, and residual material $2.00 \pm 3.37$ (Fig. 3a-f).

\section{Implant assessment}

The ISQ values were calculated during the placement and loading (4 months after placement) [14]. The mean difference in ISQ values was $2.18 \pm 0.28$ which was statistically significant $(p=0.00)$. The crestal bone level with respect to implants was calculated on each implant during the loading and 1-year post-loading using intraoral periapical radiographs. The mean difference was $0.23 \pm 0.03$ which was statistically significant $(p=0.00)$ (Fig. $4 \mathrm{a}-\mathrm{f})$.

\section{Discussion}

Araujo and Lindhe concluded and stated that "leaving the periosteum in place decreases the resorption rate of the extraction socket." [15] Benex extraction system, a time-tested atraumatic extraction system, was thus incorporated in this study $[4,16,17]$. This calcium phosphosilicate putty exhibits an interesting property called osteostimulation apart from osteoconduction. On contact with body fluids, there is an immediate exchange of ions which results in a physiochemical bond between the bioglass, soft tissue, and bone. This results in the formation of a hydroxyl-carbonate apatite (HCA) layer, a biological apatite identical to the mineral phase of the bone, which allows for more rapid repair and regeneration of the bone than other synthetic graft materials $[18,19]$. This alloplast stimulates the genes that control osteoblast differentiation and proliferation [20, 21]. Besides these, its ease of application, versatility, and usage like containment in the socket and ability to soften under pressure while loading makes the material more user-friendly. According to Pietrokovski, dense trabecular bone was formed in extraction sockets [22]. After bone grafting, PRF, a second-generation platelet concentrate, with its unique preparation technique, allows trapping of at least $95 \%$ of the platelets of the collected blood into a fibrin mesh which can then be easily manipulated into a membrane and transferred to any surgical site for the slow release of growth factors (GFs) from the platelet granules [23]. After PRF placement, a collagen plug was placed for the protection of blood clot, exclusion of gingival connective tissue, and provision of a secluded space into which osteogenic cells can migrate which are vital for bone regeneration [24]. Stabilization of the collagen plug atop the grafted bone was achieved by mattress suture. In this study, the postoperative healing of all the patients was uneventful and no complications were reported.

The combination of biomaterials used in this study satisfies the principles of bone regeneration. Primary wound closure was attained with atraumatic flapless extraction, angiogenesis was induced by autologous PRF placed, and space maintenance was achieved by the osteoconductive property of calcium phosphosilicate while the stability of the wound could be attributed to the collagen plug and mattress sutures placed after grafting [6].

On the histomorphometric evaluation of the bone core samples obtained at 6 months postoperative from the baseline, the overall mean value of the newly

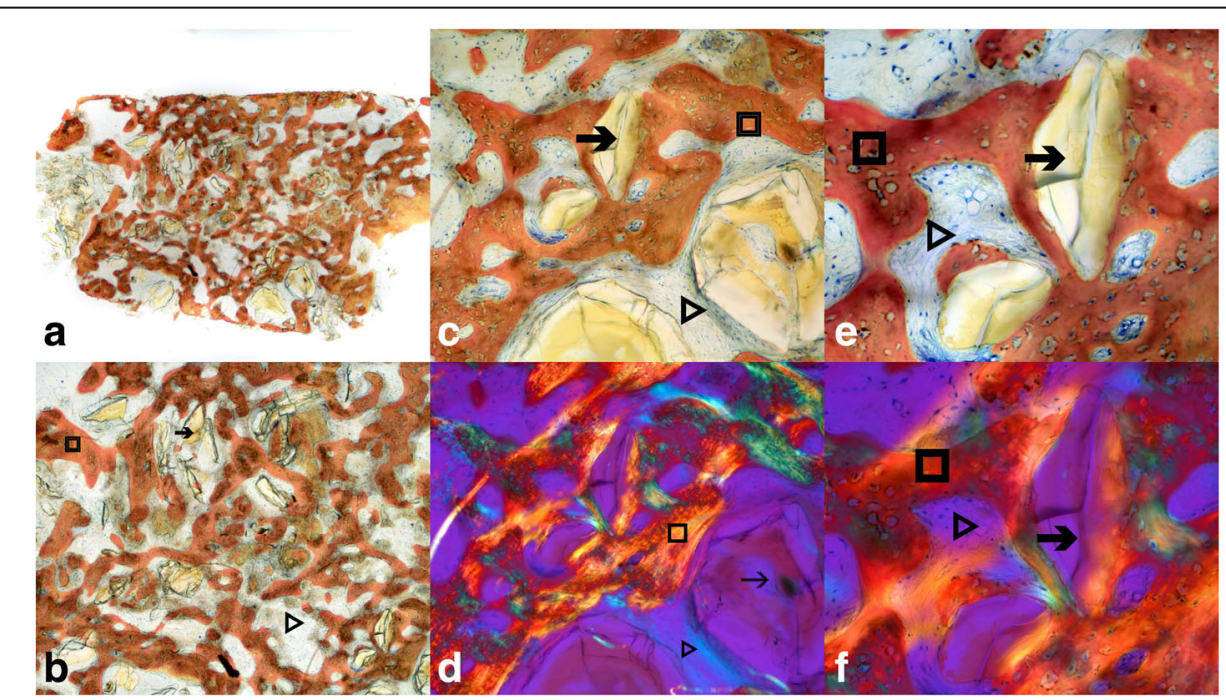

Fig. 3 Histologic picture of harvested core in low $\times 10(\mathbf{a})$, medium $\times 20(\mathbf{b})$, high $\times 40(\mathbf{c}$, d), and very high $\times 100$ (e, $\mathbf{f})$ magnifications under direct $(\mathbf{a}-\mathbf{e})$ and polarized $(\mathbf{d}, \mathbf{f})$ light. Histological picture of undecalcified section reveals vital bone lined by osteoblasts and embedded osteocytes (square-shaped marker). The amorphous areas of graft material surrounded by the vital bone are evident with collagenous tissue inbetween. The trabecular spaces stained blue are seen with vascular elements (triangle-shaped marker). The new bone growth adherent to graft suggests the facilitation of bone growth by graft. The lack of inflammation suggests acceptance/absence of rejection of graft material (arrowshaped marker) by the host bone 


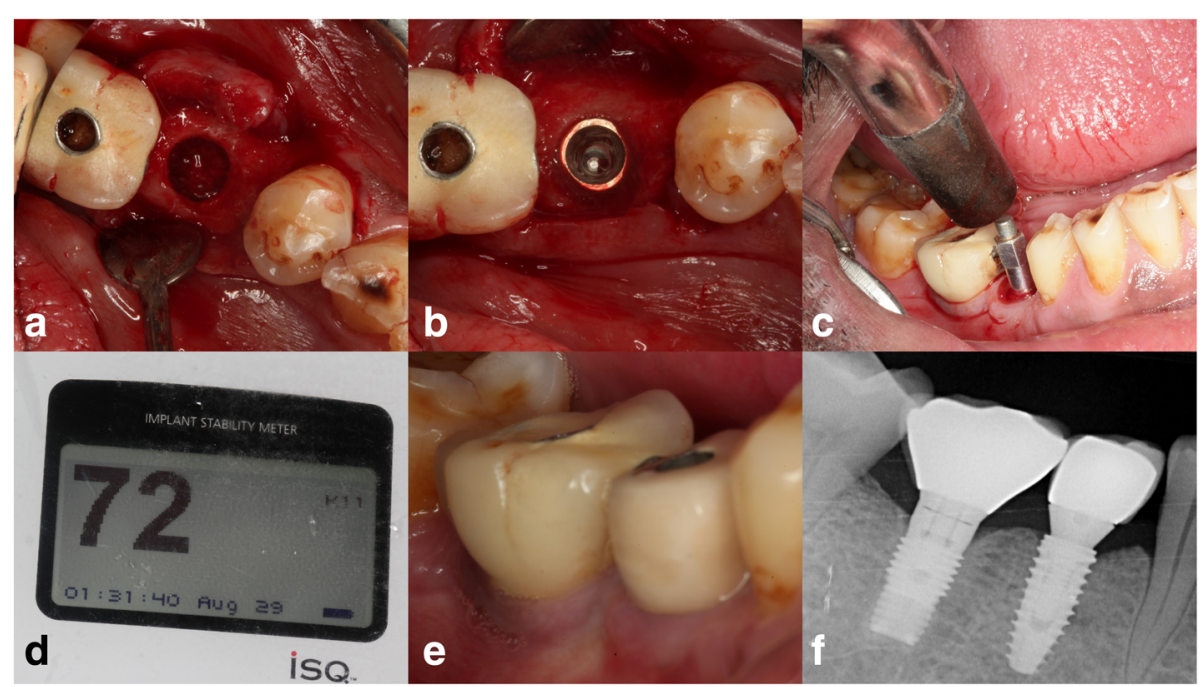

Fig. 4 The healed socket after core harvesting (a) and implant placement (b). The stability implant placed is measured using smart peg in ISQ units $(\mathbf{c}, \mathbf{d})$. The clinical and radiographic appearance of prosthesis delivered with 1-year follow-up $(\mathbf{e}, \mathbf{f})$

formed vital bone area fraction was $54.5 \pm 16.76 \%$. The formation of new well-mineralized vital trabecular bone was found in all the examined sections. The new bone was organized in trabeculae, with collagen fibers arranged in a meshwork pattern and osteocytes randomly distributed within the trabeculae in large spindle-shaped lacunae. These findings are in agreement with the previous studies [9, 25-27]. The 6 months post-grafting histomorphometric results of our study are parallel to the results of the meta-analysis evaluating the alloplast-mediated regeneration in extractions sockets [28]. A similar study was recently published wherein the soft tissue parameters pertained to healing index, while this study had standardized the parameter measurements using an acrylic stent with metallic wire which was preserved throughout the study period, for accurate measurements [29].

The 1-year success rate of the 262 implants placed in sockets grafted with calcium phosphosilicate putty was is $98.1 \%$ in a recent retrospective study [30]. Our study presents a $100 \%$ survival rate of implants, with predictable implant stability quotient values even after 1-year post-loading. Around $87 \%$ of implants exhibited an ISQ value above 65 which states that the quality of the augment bone is of type 1 [31]. The level of crestal bone around implants was minimal and said to be consistent with that of Kim et al. 2015 [32].

\section{Conclusion}

Calcium phosphosilicate putty enriched with PRF and collagen plug is a predictable material for alveolar ridge preservation procedures. All the implants placed in these grafted sites were successful with acceptable stability which states this biomaterial could be considered as one of the novel grafts available with advantages of ease of handling and liable results. More studies with long-term follow-up are to be invited and comparative studies with gold standard materials are to be encouraged to provide foolproof data on different bone grafts and bone substitute materials.

\section{Abbreviations \\ \%: Percentage; ${ }^{\bullet}$ : Recognized; ASA: American Society of Anesthesiologists; GF: Growth factor; HCA: Hydroxyl-carbonate apatite; HCl: Hydrochloride; ISQ: Implant stability quotient; PRF: Platelet-rich fibrin; UNC: University of North Carolina}

\section{Acknowledgements \\ Not applicable.}

\section{Authors' contributions}

TKAB contributed to the concepts, design, definition of intellectual content, literature search, clinical studies, experimental studies, data acquisition, data analysis, statistical analysis, manuscript preparation, manuscript editing, and manuscript review. CNT contributed to the concepts, design, definition of intellectual content, literature search, clinical studies, experimental studies, data acquisition, data analysis, and statistical analysis. DGPS contributed to the design, definition of intellectual content, literature search, clinical studies, experimental studies, data acquisition, data analysis, statistical analysis, manuscript preparation, manuscript editing, and manuscript review. TMG contributed to the data acquisition, data analysis, statistical analysis, manuscript preparation, manuscript editing, and manuscript review. MDS contributed to the data acquisition, data analysis, statistical analysis, manuscript preparation, manuscript editing, and manuscript review. All authors read and approved the final manuscript.

\section{Funding}

Not applicable.

\section{Availability of data and materials}

The clinical data and material required for the study were secured from the outpatient Department of Periodontics, Bapuji Dental College and Hospital.

\section{Ethics approval and consent to participate}

All procedures performed in this study involving human participants were in accordance with the ethical standards of the institutional review board according to the principles of the World Medical Health Association 
Declaration of Helsinki 2000 for medical research in human subjects and its later amendments or comparable ethical standards. Informed consent was obtained from all individual participants included in the study.

\section{Consent for publication}

Informed consent was obtained from all the authors of the manuscript.

\section{Competing interests}

The authors declare that they have no competing interests.

\section{Author details}

'Department of Periodontics, Bapuji Dental College and Hospital, Davangere, Karnataka 577004, India. ${ }^{2}$ Happy smiles Dental Care, Vidyanagar, Davangere, Karnataka 577004, India. ${ }^{3}$ Consultant Periodontist, Guntur, Andhra Pradesh 522006, India.

Received: 31 May 2019 Accepted: 22 July 2019

Published online: 02 September 2019

\section{References}

1. Handelsman M (2006) Surgical guidelines for dental implant placement. $\mathrm{Br}$ Dent J 201:139-152. https://doi.org/10.1038/sj.bdj.4813947

2. Schropp L, Wenzel A, Kostopoulos L, Karring T (2003) Bone healing and soft tissue contour changes following single-tooth extraction: a clinical and radiographic 12-month prospective study. Int J Periodontics Restorative Dent 23:313-323

3. Pagni G, Pellegrini G, Giannobile WW, Rasperini G (2012) Postextraction alveolar ridge preservation: biological basis and treatments. Int J Dent 2012: 151030. https://doi.org/10.1155/2012/151030

4. Muska E, Walter C, Knight A, Taneja P, Bulsara Y, Hahn M et al (2013) Atraumatic vertical tooth extraction: a proof of principle clinical study of a novel system. Oral Surg Oral Med Oral Pathol Oral Radiol 116:e303-e310. https://doi.org/10.1016/j.000o.2011.11.037

5. Ten Heggeler JM, Slot DE, Van der Weijden GA (2011) Effect of socket preservation therapies following tooth extraction in non-molar regions in humans: a systematic review. Clin Oral Implants Res 22:779-788. https://doi. org/10.1111/j.1600-0501.2010.02064.x

6. Wang $H L$, Boyapati $L$ (2006) "PASS" principles for predictable bone regeneration. Implant Dent 15:8-17. https://doi.org/10.1097/01.id.00002 04762.39826.0f

7. Troiano G, Zhurakivska K, Lo Muzio L, Laino L, Cicciù M, Lo Russo L (2017) Combination of bone graft and resorbable membrane for alveolar ridge preservation: a systematic review, meta-analysis and trial sequential analysis. J Periodontol:1-17. https://doi.org/10.1902/jop.2017.170241 [Epub ahead of print]

8. Loe H, Silness J (1963) Periodontal disease in pregnancy I. Prevalence and severity. Acta Odontol Scand 21:533-551

9. Silness J, Loe H (1964) Periodontal disease in pregnancy II. Correlation between oral hygiene and periodontal conditions. Acta Odontol Scand 22:112-134

10. Kutkut A, Andreana S, Kim H, Monaco E (2012) Extraction socket preservation graft prior to implant placement with calcium sulfate hemihydrate and platelet-rich plasma: a clinical and histomorphometry study in human subjects. J Periodontol 83:401-409. https://doi.org/10.1 902/jop.2011.110237

11. Cox JF, Zarb GA (1987) The longitudinal clinical efficacy of osseointegrated dental implants: a 3-year report. Int J Oral Maxillofac Implants 2:91-100

12. Tan K, Pjetursson BE, Lang NP, Chan ES (2004) A systematic review of the survival and complication rates of fixed partial dentures (FPDs) after an observation period of at least 5 years. III. Conventional FPDs. Clin Oral Implants Res 15:654-666. https://doi.org/10.1111/j.1600-0501.2004.01118.x

13. Falisi G, Galli M, Velasquez PV, Rivera JC, Di Paolo C (2013) Implant stability evaluation by resonance frequency analysis in the fit lock technique. A clinical study. Ann Stomatol (Roma) 4:196-203

14. Vanden Bogaerde L, Sennerby L (2016) A randomized case-series study comparing the stability of implant with two different surfaces placed in fresh extraction sockets and immediately loaded. Int J Dent:8424931. https://doi.org/10.1155/2016/8424931

15. Araujo MG, Lindhe J (2009) Ridge alterations following tooth extraction with and without flap elevation. An experimental study in the dog. Clin Oral Implants Res 20:545-549. https://doi.org/10.1111/j.1600-0501.2008.01703.x

16. Saund D, Dietrich T (2013) Minimally-invasive tooth extraction: doorknobs and strings revisited. Dent Update 40:325-330
17. Thalmair T, Fickl S, Schneider D, Hinze M, Wachtel H (2013) Dimensional alterations of extraction sites after different alveolar ridge preservation techniques - a volumetric study. J Clin Periodontol 40:721-727. https://doi. org/10.1111/jcpe.12111

18. Shapoff CA, Alexander DC, Clark AE (1997) Clinical use of a bioactive glass particulate in the treatment of human osseous defects. Compendium 18:352-363

19. Wilson J, Low SB (1992) Bioactive ceramics for periodontal treatment: comparative studies in the Patus monkey. J Appl Biomater 3:123-129. https://doi.org/10.1002/jab.770030208

20. Gonshor A, Lanka M, Saroff SA, Joachim FPC, Charon JA (2011) Histologic and clinical evaluation of bioactive calcium phosphosilicate bone graft material in post extraction alveolar sockets. J Implant Adv Clinical Dent 3: 21-31. https://doi.org/10.5005/jp-journals-10012-1040

21. Jell G, Notingher I, Tsigkou O, Notingher P, Polak JM, Hench LL, Stevens MM (2008) Bioactive glass induced osteoblast differentiation: a noninvasive spectroscopic study. J Biomed Mater Res 6:31-40. https:// doi.org/10.1002/jbm.a.31542

22. Pietrokovski J (1975) The bony residual ridge in man. J Prosthet Dent 34:456-462

23. Ehrenfest DMD, Corso MD, Diss A, Mouhyi J, Charrier JB (2010) Threedimensional architecture and cell composition of a Choukroun's plateletrich fibrin clot and membrane. J Periodontol 81:546-555. https://doi.org/1 0.1902/jop.2009.090531

24. Lang NP, Ha"mmerle CH, Bra"gger U, Lehmann B, Nyman SR (1994) Guided tissue regeneration in jawbone defects prior to implant placement. Clin Ora Implants Res 5:92-97

25. Froum S, Cho SC, Rosenberg E, Rohrer M, Tarnow D (2002) Histological comparison of healing extraction sockets implanted with bioactive glass or demineralized freeze-dried bone allograft: a pilot study. J Periodonto 73:94-102. https://doi.org/10.1902/jop.2002.73.1.94

26. Barone A, Aldini NN, Fini M, Giardino R, Guirado JLC, Covani U (2008) Xenograft versus extraction alone for ridge preservation after tooth removal: a clinical and histomorphometric study. J Periodontol 79:1370-1377. https:// doi.org/10.1902/jop.2008.070628

27. Ioannou AL, Kotsakis GA, Kumar T, Hinrichs JE, Romanos G (2015) Evaluation of the bone regeneration potential of bioactive glass in implant site development surgeries: a systematic review of the literature. Clin Oral Investig 19:181-191. https://doi.org/10.1007/s00784-014-1376-1

28. De Risi V, Clementini M, Vittorini G, Mannocci A, De Sanctis M (2015) Alveolar ridge preservation techniques: a systematic review and metaanalysis of histological and histomorphometrical data. Clin Oral Implants Res 26:50-68. https://doi.org/10.1111/clr.12288

29. Maiorana C, Poli PP, Deflorian M, Testori T, Mandelli F, Nagursky H et al (2017) Alveolar socket preservation with demineralised bovine bone mineral and a collagen matrix. J Periodontal Implant Sci 47:194-210. https://doi. org/10.5051/jpis.2017.47.4.194

30. Babbush CA, Kanawati A (2015) Clinical evaluation of 262 osseointegrated implants placed in sites grafted with calcium phosphosilicate putty: a retrospective study. J Oral Implantol 41:63-69. https://doi.org/10.1563/aaid-joi-D-13-00336

31. Yoon HG, Heo SJ, Koak JY, Kim SK, Lee SY (2011) Effect of bone quality and implant surgical technique on implant stability quotient (ISQ) value. J Adv Prosthodont 3:10-15. https://doi.org/10.4047/jap.2011.3.1.10

32. Kim SY, Dodson TB, Do DT, Wadhwa G, Chuang SK (2015) Factors associated with crestal bone loss following dental implant placement in a longitudinal follow-up study. J Oral Implantol 41:579-585. https://doi. org/10.1563/aaid-joi-D-12-00193

\section{Publisher's Note}

Springer Nature remains neutral with regard to jurisdictional claims in published maps and institutional affiliations. 